\title{
A Comprehensive Framework for Smart Cities
}

\author{
Giovanni Maccani ${ }^{1}$, Brian Donnellan ${ }^{1}$ and Markus Helfert ${ }^{2}$ \\ ${ }^{1}$ School of Business, National University of Ireland, Maynooth, Ireland \\ ${ }^{2}$ School of Computing, Dublin City University, Dublin, Ireland
}

Keywords: Smart City, Open Innovation Ecosystems, Governance, ICTs, Urban Development.

\begin{abstract}
In this paper Smart City initiatives will be explored from the perspective of the enabler factors required for such intitiatives to be successful. In detail, we see smart cities made of five collectively exhaustive dimensions, i.e. Technology, Social Infrastructure, People-Private-Public Partnerships, Governance and Management, and Smart Information Services. Thus, after a brief introduction of the domain of analysis, the starting point will be a systematic review of the literature. Then we will describe each perspective explaining why and how it has to be considered. Finally we will propose some discussions, in particular around the applicability of our framework for embedded assessment and measurement tools (e.g. Balanced Scorecard).
\end{abstract}

\section{INTRODUCTION}

Since the Copenhagen summit (2009), there is a growing perspective that "nations talk, cities act". Cities are more and more characterized by "megatrends" which are going to crash their balances (Kanter et al., 2009). Particularly the steady growth of urbanisation (by 2030 over $60 \%$ of global population will live in cities), demographic change (by 2030 the over 65 generation will almost double, from $7 \%$ to $13 \%$ ), and climate change concerns (cities are now responsible for $80 \%$ of the global GHG emissions) (Mulligan, 2010), require a quick and radical reaction. Moreover, the economic crisis and the consequential urgency to undertake disruptive innovation can provide the impetus to overcome the resistance to change, turning the problems into opportunities.

The Smart City concept is emerging as a way to tackle and solve the problems arising from these mega-trends. This term is understood as a certain intellectual ability that addresses several innovative socio-technical and socio-economic aspects of growth (Zygiaris, 2012). However, despite researchers, multinational companies as well as governments are strongly pushing towards smarter approaches for cities, it is still missing a common understanding and an embedded well acknowledged definition of such initiative (Caragliu et al., 2011). The discussion in this field revolves around diverse concepts and issues such as "Digital City"
(Besselaar et al., 2005), "Intelligent City" (Komninos, 2008), "Creative City" (Hall, 2000), "Knowledge City" (Dirks, 2009), "Ubiquitous City" (Lee, 2008), "Smart Communities" (Kanter et al., 2009), and more. Thus there is a growing need to reflect on this concept, its construction and underlying assumptions to enable transparency and new readings.

So far literature focused on many aspects that can be understood as parts of the Smart City initiative (e.g. ICT infrastructure, cities' critical services, smart economies, and so on), but attempts to holistically and systematically tackle the Smart City concept are still almost lacking. Furthermore, because of its network nature, a city should be described using a more truthful and realistic model representation based on a network system with the expression of relations between elements (Lombardi et al., 2011). As a consequence we aim at the development of a comprehensive framework for Smart Cities. We believe that through the careful description of each element that builds up such initiatives, and the identification of the relationships between these key components, we can provide a systematic conceptualization of the strategy and the ideas arising from the literature. Its development will allow the construction of measuring frameworks, enabling an easy-to-read format for a better understanding by the huge amount of stakeholders involved, and it will be the fundamental starting point for supporting software-based 
decision-making processes (for example Analytical Network Process (Saaty, 2005)). It will be also a tool to communicate, and overcome resistances to change by all the actors that are somehow engaged in Smart Cities development, to move forward towards its real holistic implementation.

To do that, the first step was a careful review and analysis of the existing literature. Then within this paper we will explain which areas we believe to be the most suitable and completed for systematically describe Smart Cities initiatives. In other words we are going to provide mutually exclusive and collectively exhaustive dimensions that fully encompass the enabler factors of Smart Cities.

\section{LITERATURE REVIEW}

Before starting in conceptualizing the dimensions of a Smart City, we need to deeply understand its core conceptual elements. The Smart City concept is still emerging, and the work of defining and categorizing it is in progress (Boulton et al., 2011). Thus, we implemented a systematic approach for a review of the existing literature. The main aim of this analysis is to provide an embedded definition of Smart City, from which we will derive the dimensions for our comprehensive framework, the main focus of this paper.

This section can be divided in two main parts. First, we extracted all the definitions available on journal papers. After finding them, we discovered a common syntactic structure that can be adapted to each definition, and that includes six categories that can be seen as the main abstract areas that have to be covered in providing a correct definition within this domain of analysis. Following these areas we developed a concept matrix, and we mapped into it, all the elements arising from the definitions. Secondly, we have also included conference papers and corporate reports into the study. Particularly, we considered all the developed frameworks provided by authors as attempts to define Smart Cities with comprehensive dimensions. After reading each paper we mapped again the dimensions in relation to the areas used for the definitions matrix.

\subsection{Definitions}

As mentioned in the brief introduction to this section, we have started analysing all the journal papers available. At this very first stage, the requirement for an article to be taken into account for our review was the presence of the word "Smart
City/Cities" either within the abstract, or the keywords, or the title of the paper itself. In total we collected 24 papers, within 7 different journals out of the 40 considered. Then, we found that only 13 papers were aligned with the aim of our review.

Going ahead, of the 13 papers considered, 11 provided a definition of Smart City (for the text definitions see Appendix 1). In order to provide a taxonomy useful for this literature review we first looked at the syntax of these sentences aiming at defining a common structure characterized by a number of main areas in which all the concepts that arise from these definitions can consistently fit. Looking at the texts of the definitions we then classified in a high level of abstraction the components of such phrases stating that: "The Smart City is a [Context] that exploits / uses / leverages / develops an [Infrastructure] with-a-certain / implementing an [Approach] supported by [Factors] to enable [processes] to achieve/ improve / enhance / increase [Goals]". In other words, every single key concept that is stated in the definitions provided in Appendix 1 is related to one of these 6 main areas, i.e. context, infrastructure, processes, approach, factors, goals. So, after checking its validity in first approximation, we've actually decomposed all the definitions into their key words or notions. Hence, with all the words/notions available, after some intuitive and obvious simplifications (e.g. "reduce urbanisation's impact on the environment" (Helal, 2011), and "ecological performances" (Kourtit et al., 2012) were both considered together with the goal "environmental sustainability" (Lombardi et al., 2011), (Tranos et al., 2012)), we developed a concept matrix in which each key word/notion is related to the author and grouped within the category it belongs to (see Appendix 2). It should be also noted that replacing randomly a single term within its area of belonging in the structure we defined above, the resulting sentence assumes a meaning as a definition of Smart Cities' domain.

After a first look at the concept matrix (see Appendix 2), we can immediately infer that the common understanding of Smart City is an initiative that exploits technologies to deliver smart information services aiming at better environmental performances, increase or add efficiencies, and improve city's competitiveness or, in other words, develop the so called Smart Economy (Giffinger et al., 2007). Another recurring aspect refers to the human/social capital as a key enabler of Smart Cities. However, insights about extremely needed innovative approaches (Schaffers et al., 2012), and new management and governance principles (Nam 
et al., 2011b) are still lacking in these definitions. Probably, most of the definitions provided come from individual research needs or prospectives (Abdulrahman et al., 2012). So, we conclude stating that only informal descriptions are available within the existing literature, rather than embedded well acknowledged definitions.

\section{$2.2 \quad$ Frameworks}

To enrich our review of the literature we have also considered all the contributions in terms of developed frameworks that, through the definition of homogeneous dimensions, aimed at defining the Smart City concept. Conference papers and corporate reports were also taken into account for this analysis.

As we did for the definitions we first extracted the useful data from each framework and then we listed all the dimensions that were chosen by each author. After that, each dimension was contextualized, consistently with its content, within the area that we found to be critical in defining Smart Cities, i.e. infrastructure, process, approach, factors and goals (see paragraph 2.1). We did not take into account the "Context" area as it is not useful for our scope at this stage. Thus, the aim of this paragraph is to provide, consistently with the categorization used for the definitions, an overview of the dimensions that have been chosen by authors in attempting at completely define the Smart City concept.

As a result of our analysis, we found that from the 18 contributions available, 7 were inspired and related to two main taxonomies: the "System of Systems" view developed by IBM (Dirks, 2009), and the study conducted in (Giffinger et al., 2007). In detail, IBM sees Smart Cities based on six core systems, i.e. people, businesses, transports, communication, water, and energy. "Instrumenting", "interconnecting", and providing them the "intelligence", would constitute what they called "System of systems" (Dirks, 2009), seen as the unique building block placed at the highest level, which enables smart services within each of the six main city's functions. Aligned with this point of view are the works of (Harrison et al., 2010, 2011), (Naphade et al., 2011). Then, the second most quoted framework starts from the definition of six core systems that are considered as the critical areas for Smart Cities. These areas are: Smart Economy, Smart Environment, Smart Living, Smart People, Smart Governance, and Smart Mobility (Giffinger et al., 2007). This path to define and conceptualize
Smart Cities was followed also by 3 more works. The first in chronological order was (Toppeta, 2010); in his paper each of the the six areas was enriched with innovative ideas. Then, one year later, the same approach was used by (Caragliu et al., 2011) and (Lombardi et al., 2011) that combined those six axes with the Triple-Helix model and particularly with the actors involved in this approach (i.e. government, businesses, and universities (Shinn, 20029).

Now we move ahead with the other contributions in terms of frameworks published to describe the Smart City. In (Kourtit et al. 2012) the smart city is conceptualized as a mix of human capital, infrastructural capital, social capital, and entrepreneurial capital. Abdulrahman, categorized Smart Cities into seven smart systems connected respectively to cities' critical activities and services. They are: Smart Grid, Smart Meter, Intelligent Transportation System, Smart Water, Smart Home, Smart Food, and Smart Healthcare (Abdulrahman et al., 2012).

Moving now to the conference papers, (Angoso, 2009) sees a Smart City as a Green City in which the technology is the main critical success factor as enabler of the proper urban network, which is able to connect vehicles, assets, employees, and people under the same "Smart City 2.0" umbrella. (Mulligan, 2010)'s vision is similar, given that he considers the Smart City's goal focused "just" on environmental sustainability performances. In his opinion a Smart City is the one which achieves the proper balance between competitiveness, environment, and quality of life, with the government as the key player. $\mathrm{He}$, together with Siemens Ltd., developed an innovative measure called "Green City Index" across eight dimensions: carbon emissions, energy, buildings, transport, waste and land use, water, air and governance. (Washburn, 2010) defined the Smart City's dimensions in relation to the services offered. Hence, the categories that in his opinion build up the Smart City are: governance, education, healthcare, public safety, real estate, transportation, and utilities. So, he provided a technology-led Smart City Blueprint. Going ahead, (Woetzel et al., 2010) provided a very interesting tool (i.e. the Urban Sustainability Index) for assessing the performances of Smart Cities. This approach is based on a quantitative evaluation across what they call the critical city's functions, that are: economic performance, social conditions, sustainable resource use, finances, and governance. (Maloney, 2011) instead, went deeper into the Smart-Sustainable City concept providing a framework that describes how a strategy should be 
built up by mayors. He considers Smart Cities as environments in which innovative ICTs are used to deliver smart services in some application areas (i.e. shopping, tourism, culture, city marketing, public and private education and health, road and public transportation, and entertainment). (Steinert et al. 2011) goes beyond the purely technological point of view and proposed two pillars (more as requirements than building blocks): the smart city broadband network and the smart city public-private approach. The first refers to technology and particularly highlights the need of a single integrated network supported by an innovative policy framework, defined by city's authorities. Furthermore the second takes into account the approach that has to be implemented for the ICT infrastructure management. Then, in (Nam et al., 2011a) the key factors are about technologies, humans, and institutions. A few months later they focused their work on the innovation component of Smart Cities (Nam et al., 2011b). Here, the dimensions they defined were: technology (to serve as a tool for innovation), organization (to manage innovation) policy (to create an enabling environment) and the surrounding context. Moreover, a useful point of view comes from EU Commission understanding of Smart Cities in terms of future actions; thus, in (Schaffers et al., 2012) were introduced many drivers and components for cities to become smarter that can be joined together into three homogeneous perspectives: technology, open innovation ecosystem (moving from the triple helix collaboration research concept to a "multiple-helix" one that includes also citizens) that has to become "user-driven" through citizens' empowerment, and urban development. Similarly, (Chourabi et al., 2012)'s aim was to provide an "integrative framework for a better understanding of Smart Cities". It included eight critical success factors: management and organization, technology, policy context, people and communities, governance, economy, built infrastructure, and natural environment. The firsts three are considered core factors, and the other as secondary ones in building a holistic strategy. Finally, (Zygiaris, 2012) defined layers as subsequent steps to reach the Smart City vision and to estimate city's smartness, rather than key perspectives. The layers (starting from the bottom) he found are: City (for its readiness), Green City (to decrease urban carbon footprint), interconnection (to develop a broadband economy), instrumentation (to ensure that the "real-time" capability), open integration (to provide an open integrated space), application (to apply the previous layers to the real city life), and innovation (to ensure smart growth).

Finally, as we did for the definitions, we mapped each dimension with the five critical areas into the concept matrix (see Appendix 3). From this table we can immediately see that none of the frameworks covered all the aspects we identified as critical in analysing the definitions. Aspects such as management and governance principles are broadly explained within these papers, and so, we also have a clearer overview of the approaches that have to be taken. However, we can affirm that there is still a lack of a comprehensive conceptualization that can be the proper base for an embedded definition, and subsequent initiatives of standardisation and integrated measurement tools.

\section{SMART CITY DIMENSIONS}

Within this third section we present the core of this document: a conceptualization of the foundation of Smart Cities. Starting from a careful and structured literature review (section 2), we developed an embedded definition of Smart City following the syntactic structure we used in analysing the existing literature; so we define Smart City as an urban area that leverages its technological and social infrastructure implementing people-private-public partnerships supported by an innovative governance in terms of policies, leadership and proper ongoing management principles, to enable smart information services, aiming at improving its critical capabilities. As a consequence we derive the dimensions for our comprehensive framework, in terms of mutually exclusive and collectively exhaustive areas that fully encompass all the enabler factors of Smart Cities. These dimensions are: "Technology", "Social Infrastructure", "Governance", "3P Partnership", and "Information Services". Each key area will be carefully described, in terms of its content and why did we choose it, within the next paragraphs.

\subsection{Technological Infrastructure}

As shown in Appendix 2 and Appendix 3, technological factors are commonly understood as one of the most important pillars, and so, nowadays ICT is an essential part of urban development, and it is necessary for all Smart Cities (Abdulrahman et al., 2012). To introduce how the technological infrastructure should look like we try here to retrace the path that has led to its creation. We believe that 
there are three fundamental milestones in building the technological background for Smart Cities, named the Spatial Intelligence of Cities (Mitchell, 2007): Ambient Intelligence (Gasson et al., 2007), Digital City (Besselaar and Koizumi, 2005), and the Intelligent City (Komninos, 2002).

- Ambient Intelligence (AI): an AI environment should facilitate human contact, be oriented towards community and cultural enhancement, help to build knowledge and skills for work, citizenship and consumer, and finally be consistent with long term sustainability ("Greening OF IT" and "Greening BY IT" (Maccani et al., 2012)). To build up the City's AI we identified three main requirements. First it is necessary, and it is a well acknowledged field in the literature, a broadband infrastructure seen as a smart combination of telecommunication networks (for their resiliency, stability, and security) and the web (for its software-driven programability easily customizable) (Steinert et al., 2011). Secondly, we have the Internet of Things (IoT) (Uckelmann et al., 2011) and the related concept of Semantic web (Ashton, 1999). An AI-oriented perspective of IoT would mean leverage the possibility to collect and analyse the digital traces left by citizens at their interaction and when they interface with widely deployed smart objects to structure the knowledge about human life, environment, and social behaviours (Guo et al. 2011). As third fundamental requirement we refer to the "instrumentation step" proposed by IBM (Dirks, 2009), in which sensors are placed across the city to enable observation of urban systems at a "micro-level" (Harrison et al. 2011). Other technologies and ICT-related concepts that can be seen as the enablers of such environment are crowd-sourcing (Estellés et al., 2012), RFID, software agents, affective computing, nanotechnologies, and biometrics (Gasson et al. 2007).

- Digital City (DC): this second milestone adds to the previous one the ubiquitous computing component (Greenfield, 2006). In other words, the key element here is a wireless infrastructure that if combined with an AI world would allow the delivery of services accessible through wireless mobile devices and enabled by SOA (Service Oriented Architecture) including web services and mobilised software application (Tanabe et al., 2002). The key turning point here is to think about machines that have to fit the human environment, rather than forcing humans to enter theirs (York et al., 2004). At this step then the Smart City is both "instrumented" and "interconnected" (Dirks, 2009).
- Intelligent City (IC): while the DC is based on digital communication, the IC provides problem solving capabilities. Thus, all ICs are DCs, but all DCs are not intelligent (Komninos, 2008). Here the digital space becomes a tool that contributes to the capacity of the community to use collective intelligence and engineer new solutions to people needs. From the previous milestone we added two key components to achieve the development of an Intelligent City: collective intelligence and cooperative distributed problem solving.

Concluding, we believe that the achievement of these three milestones described above, means the development of the technological part of the Smart City, the Spatial Intelligence of City.

\subsection{Social Infrastructure}

Developing human resources and social capital is recognized, obviously together with technology, as one of the enabling factor for Smart Cities by a large portion of literature (Toppeta, 2010). There are four critical aspects for human factors within Smart Cities, and they are (Nam et al., 2011a): Learning City (Plumb et al., 2007), Creative City (Hall, 2000), Human City (Streitz, 2009), and Knowledge City (Dirks, 2009) (concept analogous to the Learning City one). The combination of these concepts is the foundation of the Smart City's social infrastructure. In fact, through a Learning City is provided an extremely needed highly skilled information workforce (Moser, 2001), aspect related to a higher education infrastructure and better-educated individuals. Human's creativity and the development of their digital skills are crucial requirements to overcome the gaps identified by (Komninos, 2008), i.e. to turn innovative digital technologies into applications. A highly skilled human community is also a major requirement to achieve the critical mass for collective intelligence processes (Sestini, 2011a). So far in real Smart City cases there are mainly education-related initiatives in this field, and the particular focus has been on how to use ICTs to improve the education sector. Potentially ICTs can increase access from rural areas as well as from those who cannot be full time students and other benefits would come from costs reduction and from the quality of the education itself (Washburn et al., 2010). Concrete examples may be: provide life-long e-learning systems, e-books loan, collaborative design for entrepreneurs, location-based proximity services (Toppeta, 2010) and so forth. 


\subsection{Public-people-Private Partnership}

Accordingly to literature, collaboration, participation, engagement, and partnerships are key words related to this field (Odendaal, 2003) (Giffinger et al., 2007). Hence, as the third dimension of our framework we need a collaboration model to actually establish technological and social components as real enablers for Smart Cities. To promote these approaches the largest part of the literature refers to a model called "triple-helix" which focuses in particular on relations between universities, industry and government at an urban and regional scale (Shinn, 2002) (also a "multiplehelix" approach, including market, learning and knowledge, was defined (Caragliu et al., 2011)). It is generally understood "as a selection environment for knowledge creation and innovation, ushering in place-based strategies to exploit local creativity and social capital to achieve a new urban vitality, i.e. growth" (Lombardi et al., 2012). However, the potential value of co-creation through citizens, and more generally end-users, involvement is ignored in this model. As a consequence the collaboration model that has to be set up has to be between local governments, research institutes and universities, citizens and businesses. The main goal here is to develop what the EU Commission calls an UserDriven Open Innovation Ecosystem. This perspective is critical to bridge the gap between short-term city development priorities (demand pull) and long-term technological research and experimentation (technology push) (Schaffers et al., 2012). Within this perspective a great importance is given to Living Labs methodologies (Pallot, 2009). They can be seen as a User-Centred Open Innovation Ecosystem (Chesbrough, 2003), that aims at the integration of concurrent research and innovation processes (Bilgram et al., 2008) within a “3P" (Public-Private-People) Partnership. A Living Lab approach involves user communities, solution developers, research disciplines, local authorities and policy makers, and investors. So, the value is co-created and the emergence of breakthrough ideas is highly stimulated. Thus, it provides the opportunity to co-create, explore, experiment, and validate innovative Smart Cities scenarios based on technology platforms aiming at satisfying real emerging inhabitant's needs, and at improving their quality of life. Using this approach citizens are brought at the driving seats towards innovation, and their creativity skills result also improved (Ratti et al., 2011).

\subsection{Governance and Management}

A Smart City initiative was also seen by a portion of literature as the application of intelligence to city management (Boulton et al., 2011). So far, for a long time, cities' initiatives were dominated by top-down approaches (Schaffers et al., 2012). Consistently with what stated within the Public-Private-People Partnership perspective the balance between bottomup (or grassroots-driven (Sestini, 2011b)) and topdown strategies must be strengthened. Within the perspectives seen so far it can be easily inferred that sharing and integrate the information and the knowledge is one of the most critical objectives. To achieve these goals a managerial interoperability across city's smart services, applications, and organizations is extremely needed (Nam et al., 2011b).

What is critical to understand at this stage is who is going to manage the Smart City initiative. In (Witters, 2012) is described a study conducted in existing projects. Particularly, the "key initiation models" were defined and carefully described, in terms of who kicked off the projects in such case studies. The result found in his research was that the city-authority has to be the unique central management body.

A critical part of this dimension refers to leadership. One of the main challenges of local egovernment implementations is a lack of a central figure to promote progress, integrate decisions, and foster structural and procedural changes (Almazan et al., 2009). To overcome this issue, and at the same time to conceptualize a pivotal role as a unique decision-maker for a Smart City initiative, we believe that a Smart City CIO could leverage the potential of technological and social infrastructure. The rise in stature of the CIO and CTO within the city and county arena has grown or evolved, along with the ever-increasing complexity for managing communication and information technology. So, being a "cheerleader" for economic development in Smart Cities should be a natural progression for most of CIOs (Schrier, 2012). In fact, the figure of the CIO would be in the boardroom to understand the business model of a city, rather just the technical aspects of an IT department (Parker, 2005). Hence, the Smart City CIO should be responsible for defying and managing a vision for these initiatives, across the infrastructure components and services. According to (Washburn et al., 2010) CIOs are (together with technology and social infrastructure) enabler of the Smart City, providing project management expertise, best practices for 
interoperability, and being responsible for staff training and for redefine the organization. Finally a Smart City CIO should be part and the main promoter of People-Private-Public Partnerships (Shark, 2010). However, the CIO in the private sector is more flexible than the one in the public sector, since the "GCIO" (Government CIO) functions are regulated by laws (Nguyen, 2008).

Concluding, the last critical part of this block refers to the policy-context. Obviously, every single case has to deal with its political and historical background. However, some common priorities can be defined. First of all, governments should focus on an open broadband regulatory framework (Steinert et al., 2011). Laws in this way should enable safe and secure sharing of data and content seamlessly, in real time, and wirelessly, between individuals, governments, companies, and objects (e.g. sensors, devices, buildings). Secondly, an innovative policycontext should push towards the actual adoption of the "3P" Partnership approach. As a consequence, a big systematic effort from policy makers in this way is highly needed.

\subsection{Smart Information Services}

At this point of development we have all what we need to reach the Smart City mission. As a first approximation, we can state that the final goal of a Smart City is to provide smart services (Giffinger et al., 2007) in order to: improve city's inhabitants' quality of life (Hall, 2000), decrease city's carbon footprint (Angoso, 2009), reduce traffic congestions (Mulligan, 2010) and enable Intelligent Transportation Systems (Chen-Ritzo et al., 2009), improve educational (Toppeta, 2010) and healthcare sectors (Washburn et al., 2010), increase employment rate (Lombardi et al,. 2012) and define new business models to attract companies for a sustainable economic growth (Doobs et al., 2012), provide efficient and transparent e-government services (Chourabi et al., 2012), increase food supply efficiency and effectiveness (Abdulrahman et al., 2012), increase water (Venkatesen, 2010) and energy supply efficiency (Stancic, 2009), provide advanced waste management practices (Maloney, 2011), and improve public safety (Witters, 2012). All these services are enabled by the four perspectives previously described in this document.

In particular we believe we can conceptualize the main objective of this area in just one simple sentence: make sense of data. There is a huge amount of data hidden in cities (Hill, 2008), and our lives, the decisions we make, and the actions we take can be much better through data availability. We live in a "data-driven life" (Wolf, 2010). A very useful example can be the implementation of an integrated collective awareness platform (De Liddo et al., 2010) at a city's scale. Its application would be focused on participation, sharing, exchange, crowdsourcing, and open data to achieve bottom-up social innovation, through models and simulations based on real-world data and multidisciplinary understanding of the complex socio-technical interrelations (Sestini, 2011a). This approach would enable more informed decisions, a better management of resources, capacities and relationships in a transparent way. Moreover within the previous dimensions we have already provided solutions to what are generally understood by literature as main barriers to its adoption (i.e. data overload, how to achieve the critical mass, balance bottom-up and top-own initiatives etc. (Sestini, 2011b)). In fact, for instance with the proper "digital-skilled" population and a People-PrivatePublic partnership reach the critical mass is not a big challenge anymore. Other barriers, such as data overload, can be overcome with innovative technological solutions (e.g. Big Data (Schawn, 2011)).

Concluding, in section 3 we provided five dimensions that, consistently with the working definitions and the frameworks found in the existing literature, describe holistically the Smart City concept. In the next section we will present some conclusions on the results achieved with this analysis.

\section{CONCLUSIONS}

Concluding, the discussion here has been focused on Smart Cities initiatives, and particularly on a systematic approach to tackle this topic holistically. We defined five dimensions as the five main areas that encompass all the enabler factors of a Smart City: Technology, Social Infrastructure, PeoplePrivate-Public Partnership, Governance and Management, and Smart Information Services. Within the introduction section we mentioned how this conceptualization will be useful for researchers, governments and companies, in relation to innovative measurement frameworks, further processes standardizations. We want also to underline how these dimensions represent not only a framework that takes into account all aspects of Smart Cities, but also, combining these perspectives, we can have insights on how the strategy for develop 
such initiative should be built up. In detail these areas allow us to describe, in first approximation, a Smart City strategy in just one sentence. So, with the proper technological and social infrastructure, through the right organization and the appropriate management, partnerships between governments, businesses, and people can be enabled, and they are needed to overcome the existing gaps for the actual delivery of smart services to the city's community, and so achieve the Smart City mission. Keeping this sentence in mind, let's then consider how this framework can be the starting point of a (extremely needed (Lombardi et al., 2012)) systematic embedded framework for measuring Smart City performances, communicate and create awareness among stakeholders, and manage the Smart City strategy. Considering the Balanced Scorecard (BSC) (Kaplan and Norton, 1992) as a model to assess and manage a strategy (the most widely used among companies, public sector organizations (Aslani, 2009), and IT functions (Van Grembergen et al., 2005)), the taxonomy we have proposed here can be considered as a big step forward in its development. In fact, the BSC model foresees the balanced assessment of perspectives characterized by homogeneous content that enclose within them all the components of a strategy. Moreover, these perspectives have to provide an outline of the strategic path that leads to the achievement of the mission, in terms of cause-effect relationships (otherwise this would lead to what Kaplan and Norton called "a simple KPI Scorecard" (Kaplan and Norton, 1996)). Then, our approach can be definitely considered as an optimal starting point (and maybe a little bit more) for the development of an embedded measurement framework, as the BSC is. In fact, within this document, we demonstrated through a careful review of the literature (see section 2) that the five dimensions take into account all the enabler factors of Smart Cities, and furthermore they identify a strategic direction in terms of cause-effect relationships (see the sentence above in this paragraph). What is needed now is to systematically define the SMART (Specific Measurable Achievable Realistic Timely) goals for each perspective (our dimensions' description provides already some suggestions), and the subsequent critical success factors (CSF) for each goal. Finally, these CSFs are helpful to find the proper set of performance indicators in order to measure their level of achievement.

\section{REFERENCES}

Abdulrahman, A., Meshal, A., Imad, F. T. A., "Smart Cities: Survey", Journal of Advanced Computer Science and Technology Research, June 2012.

Allwinkle, S., Cruickshank, P., "Creating Smart-er Cities: An Overview", Journal of Urban Technology, April 2011.

Almazan, R., Garcia, J. R., "The Role of the CIO in a Local Government IT Strategy: The Case of Merida, Yucatàn, Mexico", Electronic Journal of eGovernment, 2009.

Angoso, J. L., "Smart Cities: the ICT Infrastructure for Ecoefficient Cities", High Level OECD Conference, 2009.

Ashton, K., "The Internet of Things' Thing”, RFID Journal, 1999.

Aslani, B., "Balanced Scorecard: A Survival Path for Public Sector”, QPR Software Plc., 2009.

Besselaar, P., Koizumi, S., "Digital City III. Information Technologies for Social Capital: Cross-cultural Perspectives", Springer, 2005

Bilgram, V., Brem, A., Voigt, K., "User Centric Innovations in New Product Development; Systematic Identification of Lead User Harnessing Interactive and Collaborative Online Tools", International Journal of Innovation Management, 2008.

Boulton, A., Brunn, S.D., Devriendt, L., "Cyber infrastructures and 'smart' world cities: physical, human, and soft infrastructure", International Handbook of Globalisation and World Cities, Cheltenham, UK, 2011.

Caragliu, A., Del Bo, C., Nijkamp, P., "Smart Cities in Europe", 3rd Central European Conference in Regional Science - CERS, 2009.

Caragliu, A., Del Bo, C., Kourtit, K., Nijkamp, P., "Performance of Smart Cities in the North Sea Basin", University of Amsterdam, 2011.

Castineira, F. G., Montenegro, E. C., Castano, F. J. G., Bravo, C. L., "Experiences Inside the Ubiquitous Oulu Smart City", IEEE Computer Society, 2011.

Chen-Ritzo, C. H., Harrison, C., Paraszczak, J., Parr, F., "Instrumenting the planet", IBM Journal of research and Development, 2009.

Chesbrough, H. W., "Open Innovation: The New imperative for creating and profiting from Technology", Boston: Harvard Business School Press, 2003.

Chourabi, H., Nam, T., Walker, S., Garcia, J.R., Mellouli, S., Nahon, K., Pardo, T. A., School, H. J., "Understanding Smart Cities: An Integrative Framework", $45^{\text {th }}$ Hawaii International Conference on System Sciences, 2012.

De Liddo, A., Buckingham Shum, S., "Cohere: A prototype for contested collective intelligence”, ACM Computer Supported Cooperative Work (CSCW), 2010.

Dirks, S., Keeling, M., “A Vision of Smarter Cities”, IBM Institute for Business Value, 2009.

Doobs, R., Remes, J., Manyika, J., Roxburgh, C., Smit, S., Schaer, F., "Urban World: Cities and the Rise of Consuming Class”, McKinsey Global Institute, June 2012. 
Estellès Arolas, E., Gonzalez Ladròn de-Guevara, "Towards an Integrated Crowdsourcing Definition", Journal of Information Science, 2012.

Flew, T., "New Media: an Introduction", Melbourne, Oxford University Press, 2008.

Gasson, M., Warwick, K., "D12.2: Study on Emerging AmI Technologies”, FIDIS Deliverables 12 (2), 2007.

Giffinger, R., Fertcher, C., Kramar, H., Kalasek, R., Meijers, E., "Smart Cities - Ranking of European Medium-size Cities", Vienna University of Technology, October 2007.

Greenfield, A., "Every ware: the Dawning Age of Ubiquitous Computing”, New Riders, pp. 11-12, 2006.

Guo, B., Zhang, D., Wang, Z., "Living with Internet of Things, The Emergence of Embedded Intelligence (CPScom-11)”, Bin Guo, April 2011.

Hall, R., "The Vision of a Smart City", $2^{\text {nd }}$ International Life Extension Technology Workshop, Paris, September 2000.

Harrison, C., Eckman, B., Hamilton, R., Hartswick, P., Kalagnanam, J., Paraszczak, J., Williams, P., "Foundation for Smarter Cities", IBM Journal of Research and Development, August 2010.

Harrison, C., Donnelly, I.A., "A Theory of Smart Cities", Journals ISSS, 2011.

Helal, S., "IT Footprinting - Groundwork for Future Smart Cities", IEEE Computer Society, 2011.

Hill, G., "The Streets as a Platform", Cities \& Places, 2008.

Kanter, R. M., Stanley, S., "A Manifesto for Smarter Cities”, Harvard Business School, 2009.

Kaplan, R.S., Norton, D.P., "The Balanced Scorecard: Measure that drive Performance"; Harvard Business Review, 1992.

Kaplan, R.S., Norton, D.P., "The Balanced Scorecard: Translating Strategy into Actions", Boston: Harvard Business School Press, 1996.

Komninos, N., "Intelligent Cities: Innovation, knowledge systems and digital spaces" London and New York, Routledge, 2002.

Komninos, N., "Intelligent Cities and Globalisation of Innovation Networks", London and New York, Routledge, 2008.

Kourtit, K., Nijkamp, P., "Smart Cities in the Innovation Age", The European Journal of Social Science Research, 2012.

Kuk, G., Janssen, M., "The Business Models and Information Architectures of Smart Cities" Journal of Urban Technology, April 2011.

Lee, M., Han, D., Jung, S., Cho, C., "A Platform for Personalised Mobile u-Health Application Development", Korean Institute for Information Scientists and Engineers, 2008.

Leydedorff, L., Deakin, M., "The Triple-Helix Model of Smart Cities: A Neo-Evolutionary Perspective”, Journal of Urban Technology, April 2011.

Lombardi, P., Giordano, S., Farouh, H., Yousef, W., "Modelling Smart City Performance", Innovation The European Journal of Social Science Research, June 2011
Maccani, G., Helfert, M., Donnellan, B., "Measuring and Capturing Green IT Knowledge in Scorecards - Green IT Balanced Scorecard", (in print) International Forum on Knowledge Asset Dynamics, Matera, 2012.

Maloney, C., "ICT for Sustainable Cities: the Green Digital Charter and other Initiatives", Launch Conference for the Smart Cities and Community Initiatives, 2011.

Mitchell, W., "Intelligent Cities", e-Journal on the Knowledge Society, 2007.

Moser, M.A., "What is Smart about the Smart Communities Movement?", EJournal, 2001.

Mulligan, L., "Smart Cities and Sustainable Technology", Siemens Ltd., 2010.

Nam, T., Prado, T. A., "Conceptualizing Smart City with Dimensions of Technology, People, and Institutions", $12^{\text {th }}$ Annual International Conference on Digital Government Research, June 2011(a).

Nam, T., Prado, T. A., "Smart City as Urban Innovation: Focusing on Management, Policy, and Context" ICEGOV Tallin, Estonia, September 2011(b).

Naphade, M., Banavar, G., Harrison, C., Paraszczak, J., Morris, R., "Smart Cities and their Innovation Challanges", IEEE Computer Society, 2011.

Nguyen, H. T. T., "Strengthening ICT Leadership in Developing Countries", Electronic Journal on Information Systems in Developing Countries, 2008.

Odendaal, N., "Information and Communication Technology and Local Governance: Understanding the difference between Cities in Developed and Emerging Economies", Environment and Urban Systems, 2003.

Pallot, M., "Engaging Users into Research and Innovation: The Living Lab Approach as a User-Centred Open Innovation Ecosystem", Webergence Blog, 2009.

Parker, D., "The importance of having a CIO/CSO", WindowSecurity.com, 2005.

Plumb, D., Leverman, A., McGray, R., "The Learning City in a 'Planet of Slums", Studies in Continuing Education, 2007.

Ratti, C., Townsend, A., "The Social Nexus", Scientific American, September 2011.

Saaty, L. T., Cillo, B., "Theory and Applications of the Analytic Network Process: Decision Making with Benefits, Opportunities, Costs, and Risks", Pittsburgh: Pennsylvania: RWS Publications, 2005.

Schaffers, H., Komninos, N., Pallot, M., "Smart Cities as Innovation Ecosystems Sustained by the Future Internet", Fireball, April 2012.

Schawn, R., "Big Data is Scaling BI and Analytics", Information Management, September 2011.

Schrier, B., "CIO as a City's Cheerleader", Digital Communities, 2012, available at: http:// www.digitalcommunities.com/blogs/city-cio/CIO-asCheerleader-070812.html.

Sestini, F., "ICT Building Resilience Within Societies", $1^{\text {st }}$ Dialogue on Platforms for Collective Awareness and Action, European Commission Brussels, 2011(a).

Sestini, F., "Social Innovation Platforms for Collective Awareness and Action", European Commission, Information Society and Media, Brussels, 2011(b). 
Shark, A. R., "CIO Leadership for Cities and Counties", Public Technology Institute, 2010, available at: http://www.pti.org/index.php/ptiee1/more/626/.

Shinn, T., "The Triple Helix and New Production of Knowledge: Pre-packaged Thinking on Science and Technology", Social Studies of Science, 2002.

Stancic, Z., "Smart Electricity Distribution Network", European Communities, July 2009.

Steinert, K., Marom, R., Richard, P., Veiga, G., Witters, L., "Making Cities Smart and Sustainable", the Global Innovation Index, 2011.

Streitz, N., "Ambient Intelligence Landscapes for Realizing the Cities of the Future", $3^{\text {rd }}$ European Conference on Ambient Intelligence, Salzburg, 2009.

Strickland, E., "Cisco Bets on South Korea Smart City", IEEE Spectrum, August 2011.

Tanabe, M., Besselaar, P., Ishida, T., "Digital Cities II: Computational and Sociological Approaches", Springer-Verlag, 2002.

Toppeta, D., "The Smart City Vision: how Innovation and ICT can build smart, 'liveable', Sustainable Cities", Think! Report, 2010.

Tranos, E., Gertner, D., "Smart Networked Cities?", The European Journal of Social Science Research, 2012.

Uckelmann, D., Harrison, M., Michahelles, F., "An Architectural Approach Towards the Future Internet of Things", Architecting the Internet of Things, Berlin, Springer, 2011.

Van Grembergen, W., De Haes, S., "Measuring and Improving IT Governance Through the Balanced Scorecard", ISACA Journal, 2005.

Venkatesen, M., "ICT as an Enabler for Smart Water Management", ITU, October 2010. available at: tsbtechwatch@itu.int.

York, J., Pendharkar, P.C., "Human-Computer Interaction Issues for Mobile Computing in a Variable Work Context", Int. J. Human-Computer Studies 60, pp. 771797, 2004

Washburn, D., Sindhu, U., Balaouras, S., Dines, R. A., Hayes, N. M., Nelson, L. E., "Helping CIOs Understanding Smart City Initiatives: Defining the Smart city, Its Drivers, and the Role of the CIO", Cambridge, MA: Forrester Research, 2010.

Witters, L., "Getting Smart About Smart Cities: Understanding the Market Opportunities in the Cities of Tomorrow", Alcatel-Lucent Market Analysis, March 2012

Woetzel, J., Xiao, G., Xue, L., "The Urban Sustainability Index: a New Tool for Measuring China's Cities", McKinsey Global Institute, November 2010.

Wolf, G., "The Data-Driven Life", The New York Times, April 28, 2010.

Zygiaris, S., Smart City Reference Model: Assisting Planners to conceptualize the building of Smart City Innovation Ecosystems", Springer Science Business Media, January 2012.

\section{APPENDIX}

\section{1: Definition Table}

\begin{tabular}{|c|c|}
\hline References & Definitions \\
\hline [Kanter, 2009] & $\begin{array}{l}\text { "a smarter city infuses information into its physical infrastructure to improve } \\
\text { converiences, facilitate mobility, add efficiencies, conserve onengy, improve the } \\
\text { quality of air and water, identify problems and fux them quickly, ncover rapidly } \\
\text { from disasters, collect data to make better decisions and deploy nesourtes } \\
\text { effectively, and share data to enable collaboration across entities and domains. Its } \\
\text { operations are instrumented and guided by performance metrics, with } \\
\text { interonnections acrass sectors and silas" }\end{array}$ \\
\hline $\begin{array}{l}\text { [Harrion et al. 2010, } \\
\text { 2011] }\end{array}$ & $\begin{array}{l}\text { "Smartar Cities an wrian areas that exploit operational data, such as that arising } \\
\text { frum traffic congertion, power consumption statistics, and public safety events, to } \\
\text { optimize the operation of city services" }\end{array}$ \\
\hline$\frac{\text { [Castincina et al. }}{2010]}$ & $\begin{array}{l}\text { "Smart Cities as a means of extending ubiquitous computing services beyond the } \\
\text { traditional smart hame enviroment, forming the basis of interaction within an } \\
\text { ontine commasnity on a much langer geographical scale" }\end{array}$ \\
\hline [Helal, 2011] & $\begin{array}{l}\text { "Smart cities as a way to offer fechnology solution to bridge the widening gap } \\
\text { between supply and demand while neducing urbanisation's impact on the } \\
\text { onvironment" }\end{array}$ \\
\hline Aaphade et al. 2011] & $\begin{array}{l}\text { "Smart city relies on the we of powerful analytical techniques to ettract insights } \\
\text { from neal world events to improve urban business proceses" }\end{array}$ \\
\hline $\begin{array}{l}\text { [Lombandi et al. } \\
\text { 2011] } \square \square\end{array}$ & $\begin{array}{l}\text { "companed with the concept of digital city or intelligent city, the Smant City is not } \\
\text { limited to the role of ICT infrastructure but is mainly on the role of human } \\
\text { capitaleducation, social and nelational capital, and envitonmental issaes" }\end{array}$ \\
\hline [Franos et al. 2012] & $\begin{array}{l}\text { "smart cities can be seen to embody specific characteristics that include digital } \\
\text { infrastructure and ICT wage, emphasis on businestled urban development, the } \\
\text { social inchsion agenda via egovernance, concern with high-tech and crative } \\
\text { industries in urban growth, the importance of social capital in urban development } \\
\text { and the inclusion of avirormental and social sustainability" }\end{array}$ \\
\hline [Kouttit et al. 2012] & $\begin{array}{l}\text { "sman city as the nsult of knowledge intensive and creative strategies aiming at } \\
\text { orhancing the socio-cconomic, ecological, logistic, and competitive performance } \\
\text { of cities" }\end{array}$ \\
\hline $\begin{array}{l}\text { [Leydedorff et al. } \\
\text { 2011] }\end{array}$ & $\begin{array}{l}\text { "The triple- Helix model is needed to bootstrap the technologies to generate the } \\
\text { knowledge base for intelligent cities and their augmentation into smarter cities. } \\
\text { Such cities are smarter at exploting the intelligent city (ICT) and delivering } \\
\text { smart services" }\end{array}$ \\
\hline [Kuk et al. 2011] & $\begin{array}{l}\text { "smart city is an initiative implemented by a goverment with the ambition to } \\
\text { become full service provider" }\end{array}$ \\
\hline [Caragline et al. 2011] & $\begin{array}{l}\text { "a city is smart wher investments in human and social capital and traditional } \\
\text { (transport) and modern (ICT) communication infrastructure fuel suttainable } \\
\text { economic growth and a high quality of life, with a wise management of natural } \\
\text { nesounces, through participatory governance" }\end{array}$ \\
\hline
\end{tabular}




\section{2: Definition Concept Matrix}

\begin{tabular}{|c|c|c|c|c|c|c|c|c|c|c|c|c|c|c|c|c|c|c|c|c|c|c|c|c|c|c|c|c|c|c|c|}
\hline \multirow[b]{2}{*}{$\begin{array}{l}\text { Definitions } \\
\text { References: }\end{array}$} & \multicolumn{5}{|c|}{ Context } & \multicolumn{7}{|c|}{ Infrastructure } & \multicolumn{4}{|c|}{ Processes } & \multicolumn{5}{|c|}{ Approach } & \multicolumn{2}{|c|}{ Factors } & \multicolumn{8}{|c|}{ Goals } \\
\hline & & $\frac{5}{2}$ & 글 & 苞 & 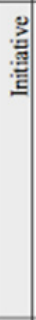 & 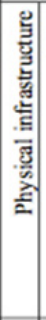 & & 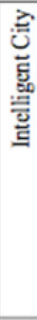 & 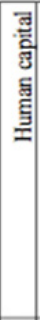 & 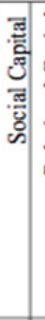 & & 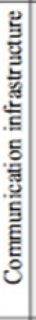 & 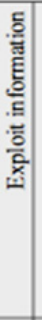 & 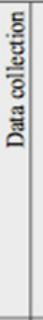 & 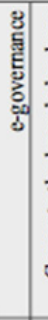 & 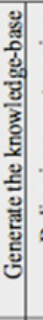 & : & 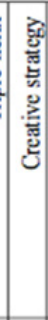 & 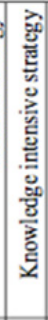 & 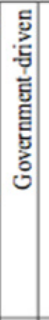 & 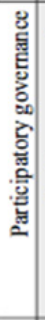 & 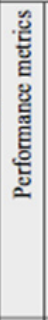 & 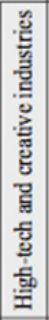 & 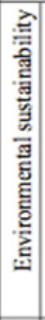 & 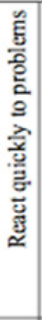 & 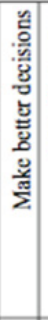 & 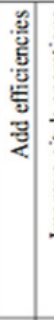 & 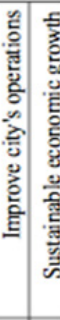 & 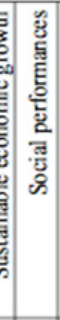 & & 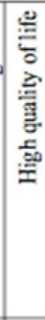 \\
\hline [Kanter] & & & & & & $x$ & & & & & & & $\mathrm{x}$ & $\mathrm{x}$ & & & $x$ & & & & & $\mathrm{x}$ & & $\mathrm{x}$ & $\mathrm{x}$ & $\mathrm{x}$ & $\mathrm{x}$ & & & & \\
\hline [Harrison] & $\mathrm{x}$ & & & & & & & & & & & & & & & & & & & & & & & & & & & $x$ & & & \\
\hline [Castineira] & & $x$ & & & & & & $\mathrm{x}$ & & & & & & & & & $x$ & & & & & & & & & & & & & & \\
\hline [Helal] & & & $\mathrm{x}$ & & & & $\mathrm{x}$ & & & 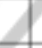 & & & & & & & 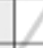 & & & & & - & & $\mathrm{x}$ & & & & $x$ & & & \\
\hline [Naphade] & & & & & & & $\mathrm{x}$ & & 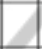 & 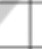 & & & & $\mathrm{x}$ & & & & & & & & & & 7 & & & & $x$ & & & \\
\hline [Lombardi] & & & & ב & & & $\mathrm{x}$ & & $\mathrm{x}$ & $x$ & $\mathrm{x}$ & & & & & 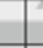 & & & 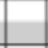 & & & 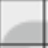 & & $\mathrm{x}$ & & & 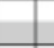 & & 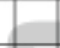 & & \\
\hline [Tranos] & & & & & & & $\mathrm{x}$ & & & $\mathrm{x}$ & & & & & $x$ & 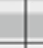 & 1 & & 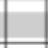 & 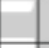 & & & $\mathrm{x}$ & $x$ & & 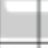 & & $x$ & $x$ & $\mathrm{x}$ & \\
\hline [Kourtit] & & & & $x$ & & & 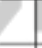 & 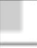 & & & & & & & 7 & & & $x$ & $x$ & & & V & & $x$ & & 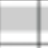 & & $\begin{array}{ll}x & x \\
\end{array}$ & $x$ & & \\
\hline [Leydedorff] & & & & & & & $\mathrm{x}$ & $\mathrm{x}$ & & & & & & 4 & $\mathrm{x}$ & $x \times$ & $x$ & & & & & & 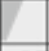 & & & & & & & & \\
\hline [Kuk] $\square 1 \equiv$ & $\Delta$ & 맘 & 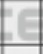 & E & $\mathrm{x}$ & & J & 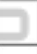 & & 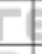 & & 들 & $H$ & 11 & $\sqrt{E}$ & $\underline{E}$ & C & & E4 & $\mathrm{x}$ & I & P & 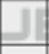 & E & $=$ & 몽 & 1 & 7 & 든 & IN & JS \\
\hline [Caragliu] & & & & & & & $\mathrm{x}$ & & $\mathrm{x}$ & $\mathrm{x}$ & 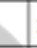 & $\mathrm{x}$ & 7 & & & 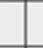 & & & 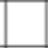 & & $\mathrm{x}$ & 7 & & & & 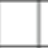 & & & & & $\mathrm{x}$ \\
\hline Tot. & 1 & 1 & 1 & 1 & 1 & 1 & 6 & 2 & 2 & 3 & 1 & 1 & 1 & 2 & \begin{tabular}{l|l}
1 & 1 \\
\end{tabular} & $1 \mid 1$ & 3 & 1 & 1 & 1 & 1 & 1 & 1 & 5 & 1 & 1 & \begin{tabular}{l|l}
1 & 3 \\
\end{tabular} & 33 & 2 & 1 & 1 \\
\hline Tot. per Area & & & 5 & & & & & & 16 & & & & & & 6 & & & & 7 & & & 2 & 2 & & & & & 18 & & & \\
\hline
\end{tabular}

\section{3: Frameworks Concept Matrix}

\begin{tabular}{|c|c|c|c|c|c|c|c|c|c|c|c|c|c|c|c|c|c|c|c|c|c|c|c|c|c|c|c|c|}
\hline \multirow[b]{2}{*}{$\begin{array}{l}\text { Frameworks } \\
\text { References }\end{array}$} & \multicolumn{7}{|c|}{ Infrastructure } & & \multicolumn{6}{|c|}{ Factors } & \multicolumn{3}{|c|}{ Approach } & \multicolumn{11}{|c|}{ Goals } \\
\hline & $\underline{\underline{\Xi}}$ & 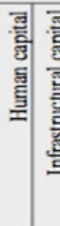 & 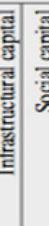 & 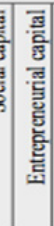 & 믈 & & & & 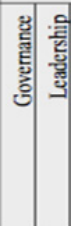 & : & 鄫 & 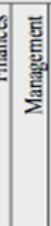 & & 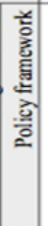 & 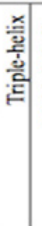 & 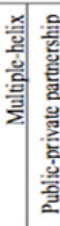 & 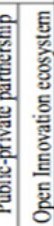 & 彦 & 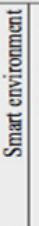 & 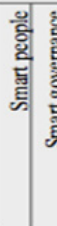 & 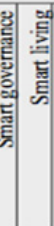 & 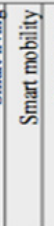 & & & 墨 & 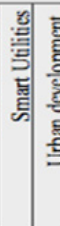 & 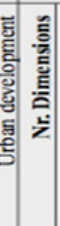 & \\
\hline [Dirks] & $\mathrm{x}$ & & & & & & & $\mathrm{x}$ & & & & & & & & & & & & & & & & & & & 2 & \\
\hline [Harrison] & $x$ & & & & & & & $\mathbf{x}$ & & & & & & & & & & & & & & & & & & & 2 & 2 \\
\hline [Naphade] & $x$ & & & & & & & $x$ & & & & & & & & & & & & & & & & & & & 2 & 2 \\
\hline [Giffinger] & & & & & & & & & & & & & & & & & & $\mathrm{x}$ & $\mathrm{x}$ & \begin{tabular}{l|l}
$x$ & $x$ \\
\end{tabular} & $\mathrm{x}$ & $x$ & & & & & 6 & 1 \\
\hline [Kourtit] & & \begin{tabular}{l|l}
$\mathbf{x}$ & $\mathbf{x}$ \\
\end{tabular} & \begin{tabular}{l|l}
$x$ & $x$ \\
\end{tabular} & $\mathrm{x}$ & & & & & & & & & & & & & & & & & & & & & & & 4 & 1 \\
\hline [Abdulrahm & & & & & $\mathrm{x}$ & $\mathrm{x}$ & & & & & & & & & & & & & & & & $\mathrm{x}$ & \begin{tabular}{l|l|}
$x$ & $x$ \\
\end{tabular} & \begin{tabular}{|l|}
$x$ \\
\end{tabular} & $x$ & & 7 & 2 \\
\hline [Caragliu] & & & & & & & & & & & & & & & & $\mathrm{x}$ & & $\mathrm{x}$ & $\mathbf{x}$ & \begin{tabular}{l|l}
$x$ & $x$ \\
\end{tabular} & $\mathrm{x}$ & $\mathrm{x}$ & & & & & 7 & 2 \\
\hline [Lombardi] & & & & & & & & & & & & & & & $\mathrm{x}$ & & & $\mathbf{x}$ & $\mathbf{x}$ & \begin{tabular}{l|l}
$x$ & $x$ \\
\end{tabular} & $\mathrm{x}$ & $\mathbf{x}$ & & & & & 7 & 2 \\
\hline [Angoso] & $x$ & & & & & & & & & & & & & & & & & & $\mathbf{x}$ & & & & & & & & 2 & 2 \\
\hline [Mulligan] & & & & & & & & & \begin{tabular}{|l|l}
$\mathbf{x}$ & \\
\end{tabular} & & & & & & & & & $\mathbf{x}$ & $\mathbf{x}$ & & $\mathrm{x}$ & & & & & & 4 & 2 \\
\hline [Washburn] & $x$ & & & & & & & & \begin{tabular}{|l|} 
\\
\end{tabular} & & & & & & & & & & & \begin{tabular}{l|l}
$x$ & $x$ \\
\end{tabular} & $\mathrm{x}$ & $x$ & $x$ & & & $\mathrm{x}$ & 8 & 3 \\
\hline [Woetzel] & & & & & & & & & $\mathrm{x}$ & & $\mathrm{x}$ & & & & & & & $\mathrm{x}$ & $\mathrm{x}$ & & & $\mathrm{x}$ & & & & & 5 & 2 \\
\hline [Maloney] & $x$ & & & & & & & $\mathrm{x}$ & & & & & & & & & & & & & & & & & & & 2 & 2 \\
\hline [Steinert] & $x$ & & & & & & & & & & & & & $x$ & & $\mathrm{x}$ & & & & & & & & & & & 3 & 3 \\
\hline$[\mathrm{Nam}]$ & $x$ & & & & & & & & & & & & $\mathrm{x}$ & $\mathrm{x}$ & & & & & & & & & & & & & 3 & 2 \\
\hline [Schaffers] & $x$ & & & & & & & & & & & & & & & & $x$ & & & & & & & & & $\mathrm{x}$ & \begin{tabular}{l|l|} 
& 3 \\
\end{tabular} & 3 \\
\hline [Chourabi] & $x$ & & & & & & $\mathrm{x}$ & & $\mathbf{x}$ & & $\mathrm{x}$ & $\mathrm{x}$ & $\mathrm{x}$ & $x$ & & & & $\mathrm{x}$ & $\mathrm{x}$ & & & & & & & & 9 & 3 \\
\hline [Zygiaris] & $\mathrm{x}$ & & & & & & & & & $\mathbf{x}$ & & & & & & & & & $x$ & & & & & & & & 3 & 3 \\
\hline Total dim. & 11 & $1: 1$ & \begin{tabular}{l|l}
1 & 1 \\
\end{tabular} & 1 & \begin{tabular}{|l|l|l|}
1 & \\
\end{tabular} & 1 . & 1 & 4 & \begin{tabular}{l|l|}
3 & 1 \\
\end{tabular} & 11 & 1.1 & 1 & 2 & 3 & $1]$ & \begin{tabular}{l|l}
1 & 1 \\
\end{tabular} & 1 & 6 & 8 & $4: 4$ & 4 & 6 & \begin{tabular}{l|l|}
1 & 2 \\
\end{tabular} & 21 : & $1]$ & \begin{tabular}{l|l}
1 & 1 \\
\end{tabular} & $1: 1$ & \\
\hline
\end{tabular}

